\title{
PEMBERDAYAAN PEREMPUAN AKSEPTOR KB DALAM MEMPERTAHANKAN KESEHATAN, KUALITAS HIDUP DAN PERAN YANG OPTIMAL DALAM KELUARGA
}

\author{
Muthia Mutmainnah, Indah Mawarti, Yusnilawati \\ Fakultas Kedokteran dan ilmu Kesehatan Universitas Jambi \\ Corresponding author e-mail: muthia_mutmainnah@unja.ac.id
}

\begin{abstract}
ABSTRAK
Setiap manusia memiliki kewajiban dan hak yang sama, namun dalam kenyataannya ada perubahan dalam persamaan kewajiban dan hak antara perempuan dan laki-laki. Kebanyakan saat ini perbedaan yang terlihat nyata antara perempuan dan laki-laki adalah pada masyarakat yang menganut budaya patriarki termasuk negara Indonesia. Pada masyarakat patriarki, perempuan berada dalam posisi yang tidak berdaya karena kurang bahkan tidak adanya kesempatan perempuan dalam pengambilan keputusan dalam hidupnya termasuk dalam mengambil keputusan terkait dirinya.

Selain dari peran perempuan yang kurang menguntungkan dalam pengambilan keputusan untuk menjadi akseptor KB, ketidakberdayaan perempuan dalam keluarga juga terlihat dari sulitnya perempuan melakukan kegiatan di luar keluarganya. Maka perlu adanya kegiatan yang dapat menekan antara ketimpangan perempuan baik dalam keluargamaupun masyarakat. Program KB (Keluarga Berencana) dapat dijadikan salah satu program yang diharapkan dapat meningkatkan keberdayaan perempuan. Berdasarkan latar belakang di atas, rumusan masalah dalam pengabdian ini adalah "pemberdayaan perempuan akseptor KB guna meningkatkan kesehatan, kualitas hidup dan peran yang optimal dalam keluarga di wilayah kerja Puskesmas Simpang Sungai Duren".
\end{abstract}

Kata Kunci: Pemberdayaan Perempuan, Akseptor KB

\section{PENDAHULUAN}

Indonesia adalah salah satu negara yang memiliki jumlah penduduk ke-4 terbesar di dunia setelah Negara Cina, India dan Amerika Serikat. Hal ini menunjukkan bahwa semakin banyaknya penduduk di Indonesia karena tingginya tingkat kelahiran penduduk di Indonesia. Apabila dilihat lebih dalam lagi, angka kelahiran tidak sama antara satu tempat, satu desa, satu provinsi bahkan satu negara. Namun, latar belakang pendidikan yang rendah dan kurang sejahtera memiliki tingkat kelahirnan yang lebih besar. Upaya pemerintah dalam mengendalikan laju pertumbuhan penduduk adalah melalui berbagai program salahsatunya adalah program Keluarga
Berencana (KB). Salah satu kegiatan dalam program ini adalah menyediakan konsultasi atau pelayanan keluarga berencana untuk meningkatkan kualitas dari suatu keluarga dengan kecilnya jumlah anggota suatu keluarga maka keluarga tersebut dapat meningkatkan kebutuhan konsumsi, kesehatan dan pendidikan angoota keluarganya.

Setiap manusia memiliki kewajiban dan hak yang sama, namun dalam kenyataannya ada perubahan dalam persamaan kewajiban dan hak antara perempuan dan laki-laki. Kebanyakan saat ini perbedaan yang terlihat nyata antara perempuan dan laki-laki adalah pada masyarakat yang menganut budaya patriarki termasuk negara Indonesia. Pada 
masyarakat patriarki, perempuan berada dalam posisi yang tidak berdaya karena kurang bahkan tidak adanya kesempatan perempuan dalam pengambilan keputusan dalam hidupnya termasuk dalam mengambil keputusan terkait dirinya. Sehingga ketidakberdayaan inilah yang menyebabkan perempuan dalam posisi marginal dalam bermasyarakat. Selain itu ketidakberdayaan perempuan pun terlihat dari program keluarga berencana (KB). Dalam hal ini, biasanya pengambilan keputusan untuk menjadi akseptor KB diputuskan oleh laki-laki, namun laki-laki sedikit yang menjadi akseptor KB. Pada hakikatnya, program KB tidak hanya berkaitan dengan akseptor KB saja tapi juga program pemberdayaan perempuan. Namun program pemberdayaan perempuan di dalam program KB tentu berkaitan dengan program keluarga berencana. Program KB (Keluarga Berencana) adalah program pemerintah dalam mengupayakan terwujudnya keluarga yang sehat dan berkualitas. Keberhasilan program Keluarga Berencana (KB) sangat tergantung kepada partisipasi masyarakat sehingga menurunnya tingkat pertumbuhan penduduk dan KB menjadi strategi potensial dalam meningkatkan akses perempuan serta transformasi budaya.

Pada tahun 2018 sebesar 265.015,3 juta penduduk dan pada tahun 2019 menjadi sebesar 268.074,6 juta penduduk.Jumlah proyeksi penduduk Indonesia meningkat sebesar 3 juta pada tahun 2019. Data demografi Provinsi Jambi sesuai dengan hasil dari sensus penduduk oleh BPS (Badan Pusat Statistik) memperlihatkan bahwa jumlah penduduk di Provinsi Jambi pada tahun 1990sebanyak 2.020.568 jiwa, tahun 2000 sebanyak 2.507.166 jiwa, dan tahun 2010 sebanyak 3.092.365 jiwa. Dengan demikian dapat diketahui bahwa terjadi peningkatan laju pertumbuhan penduduk di Jambi sebanyak $1,77 \%$ di tahun 1990 - 2000 dan 2,56\% pada rentang waktu 2000 - 2014. Perbandingan antara penduduk dan ratio jenis jelamin di Provinsi Jambi pada tahun 2017 yaitu laki-laki sebanyak 1.793.389 jiwa, sedangkan perempuan sebanyak 1.721.628 jiwa.4 Hal ini menunjukkanrasio bahwa jenis kelamin (lakilaki dan perempuan) adalah 104,17. Maka dari itu, program KB ini diharapkan dapat menekan laju pertumbuhan penduduk.

Selain dari peran perempuan yang kurang menguntungkan dalam pengambilan keputusan untuk menjadi akseptor KB, ketidakberdayaan perempuan dalam keluarga juga terlihat dari sulitnya perempuan melakukan kegiatan di luar keluarganya. Hal ini disebabkan pemikiran masyarakat yang masih menganut asas "banyak anak banyak rejeki". Asas tersebut menempatkan keluarga agar lebih mudah untuk menghidupi keluarga. Banyak anak akan membuat seorang ibu lebih banyak menghabiskan waktu untuk membereskan urusan rumah tangga. Banyak anak tidak menjamin perekonomian keluarga menjadi lebih baik, bahkanakan berisiko buruk untuk masa depan anak karena tanggungan berat seorang ayah untuk menghidupi keluarganya.

Jumlah Wanita Usia Subur (WUS) Indonesia merupakan jumlah terbesar di Asia Tenggara sebesar 65 juta, kemudian diikuti Vietnam 25,3 juta dan Filipina sebesar 23 juta.Indonesia merupakan negara dengan penggunaan kontrasepsi keempat tertinggidinegara ASEANsetelah Thailand $80 \%$,Kamboja sebesar $79 \%$, dan Vietnam $78 \%$. Persentase penggunaan kontrasepsi Indonesiasebesar $61 \%$ dimana Indonesia 
sudah melebihi rata-rata penggunaan kontrasepsi di negara ASEAN yaitu sebesar 2.6\%. Total Fertility Rate (TFR) Indonesia dibandingkan rata-rata dengan negasa ASEAN. Indonesia sebesar 2,6\% setelah Timor Leste 6,6\%, Filipina 3,4\%, Kamboja 3,4\%, Laos 3,3\%, dan Malaysia 2,6\%. Ratarata TFR negara-negara ASEAN yaitu $2,9 \%$. Data SDKI pada 2012 menunjukkan tren Prevalensi Penggunaan Kontrasepsi atau Contraceptive Prevalence Rate (CPR) di Indonesia sejak 1991-2012 cenderung meningkat, sementara tren Angka Fertilitas atau Total Fertility Rate (TFR) cenderung menurun. Tren ini menggambarkan bahwa meningkatnya cakupan wanita usia 15-49 tahun yang melakukan KB sejalan dengan menurunnya angka fertilitas nasional. Selain itu juga terjadi penurunan angka putus pakai menjadi 25\% dari target tahun 2018 sebesar $25 \%$ (persentase capaian 100\%) dan peningkatan penggunaan Metode Kontrasepsi Jangka Panjang (MKJP) sebesar 23,1\% dari target tahun 2018 sebesar 22,3\% (persentase capaian 103,6\%). Dari hasil data tersebut terjadi penggunaan Metode Kontrasepsi Jangka Panjang yang terkadang tidak diiringi dengan pengetahuan dari akseptor KB dalam penggunaan dan pemilihan KB. Survey pada tanggal 11 Juli 2020, peneliti melakukan wawancara secara acak terhadap 10 akseptor pengguna KB pil menunjukkan bahwa 6 akseptor pengguna KB pil mangatakan kurang paham, 2 akseptor pengguna KB suntik mengatakan ikut teman yang menggunakan KB suntik, 1 akseptor pengguna KB suntik mengatakan paham dan 1 akseptor pengguna KB IUD mengatakan sangat paham tentang KB IUD.
Berdasarkan uraian latar belakang tersebut maka perlu adanya informasi atau pemahaman pengetahuan mengenai efek ataupun manfaat KB agar perempuan tidak salah memilih dalam melakukan KB. Program KB (Keluarga Berencana) dapat dijadikan salah satu program yang diharapkan dapat secara optimal melakukan peningkatan kualitas kesehatan perempuan dan keluarga.

Berdasarkan latar belakang di atas, rumusan masalah dalam pengabdian ini adalah "pemberdayaan perempuan akseptor KB guna meningkatkan kesehatan, kualitas hidup dan peran yang optimal dalam keluarga di wilayah kerja Puskesmas Simpang Sungai Duren"

Tujuan pengabdian ini adalah sebagai upaya pemberdayaan perempuan akseptor KB guna meningkatkan kesehatan, kualitas hidup dan peran yang optimal dalam keluarga di wilayah kerja Puskesmas Simpang Sungai Duren.

\section{METODE}

\section{Prosedur Kegiatan}

Pengabdian ini bertujuan untuk untuk meningkatkan pengetahuan perempuan akseptor KB tentang penggunaan alat kontrasepsi, dan perawatan yang diperlukan agar dapat menjaga kesehatan dan mempertahankan kualitas hidup yang optimal.

\section{Tempat dan Waktu Pengabdian}

Kegiatan pengabdian masyarakat ini direncanakan akan dilakukan dengan kurun waktu 3 bulan. Partisipan pada Kegiatan pengabdian masyarakat ini adalah 120 orang, yaitu ibu yang menggunakan alat kontrasepsi di Wilayah Kerja Puskesmas Simpang Sungai 
Duren. Kegiatan pengabdian masyarakat ini dilakukan pada bulan Juli hingga 30 Oktober 2020, mulai dari survei awal yang telah dilakukan sejak Januari hingga penyusunan laporan pada akhir September 2020. Kegiatan pengabdian ini dimulai dengan melakukan survei awal ke Puskesmas Simpang Sungai Duren, melakukan observasi terhadap pelayanan keluarga berencana di Wilayah Kerja Puskesmas Simpang Sungai Duren. Penyusunan proposal. Alasan pemilihan tempat Kegiatan pengabdian masyarakat tersebut karena kunjungan ibu di poli Keluarga Berencana (KB) cukup banyak, banyaknya posyandu yang aktif dan juga untuk mendapatkan data yang akurat mengenai pengambilan keputusan ibu dalam penggunaan program Keluarga Berencana (KB). Presentasi kegiatan pengabdian direncanakan akan dilaksanakan pada akhir November 2020.

\section{Sasaran Kegiatan Pengabdian}

Kegiatan pengabdian masyarakat ini direncanakan akan dilakukan dengan kurun waktu 1 tahun. Partisipan pada Kegiatan pengabdian masyarakat ini adalah 120 orang, yaitu ibu yang menggunakan alat kontrasepsi di Wilayah Kerja Puskesmas Simpang Sungai Duren.

\section{Jadual Kegiatan}

Kegiatan pengabdian masyarakat ini direncanakan akan dilakukan dalam kurun waktu 1 tahun. Partisipan pada kegiatan pengabdian ini adalah 120 orang, yaitu ibu yang menggunakan alat kontrasepsi di Wilayah Kerja Puskesmas Simpang Sungai Duren. Kegiatan pengabdian masyarakat ini rencana dilakukan pada bulan Februari hingga 30 November 2020, mulai dari survei awal yang telah dilakukan sejak Januari hingga penyusunan laporan pada akhir November 2020. Kegiatan pengabdian ini dimulai dengan melakukan survei awal ke Puskesmas.

\section{HASIL}

Kegiatan awal yang dilakukan tim pengabdian yaitu melakukan koordinasi dengan pihak Puskesmas Simpang Sungai Duren Kabupaten Muaro Jambi dan kader setempat. Selanjutknya, melakukan kesepakatan waktu dan tempat pelaksanaan kegiatan.

Pengabdian masyarakat ini diikuti oleh 121 peserta dalam waktu 3 bulan yaitu tanggal 10 Juli 2020 dan 13 Oktober 2020. Kegiatan ini dilakukan di 5 posyandu di Wilayah Kerja Puskesmas Simpang Sungai Duren, Kabupaten Muaro Jambi. Hasil pengabdian ini dapat mewujudkan keluarga sejahtera melalui peningkatan pengetahuan ibu akan pentingnya manajeman perawatan ibu akseptor KB.

Karakteristik ibu akseptor KB di Wilayah Kerja Puskesmas Simpang Sungai Duren mayoritas berada pada kategori dewasa awal dengan rentang umur 25-36 tahun sebanyak 74\% (90 ibu) 


\section{Kategori Umur}

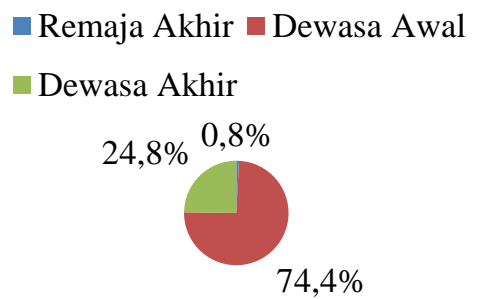

Tekanan darah ibu akseptor KB sebagian besar

(114 ibu) dan yang mengalami prehipertensi memiliki tekanan darah normal sebanyak $94 \%$ hanya $6 \%$ (7 ibu).

\section{Kategori Tekanan Darah}

- Normal $\quad$ Prehipertensi

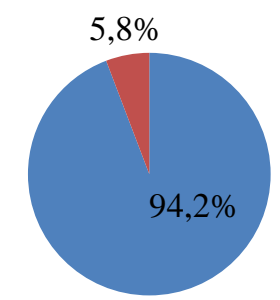

Dari 121 ibu akseptor KB, 98,3\% (119 ibu) menggunakan KB hormonal dan 1,7\% (2 ibu) KB non hormonal. Dari 119 ibu akseptor KB hormonal, 94 ibu menggunakan KB suntik 3 bulan, 23 ibu menggunakan pil, dan 2 ibu menggunakan KB suntik 1 bulan. Ibu KB non hormonal yaitu menggunakan metode kalender sebanyak 2 orang.

\section{Kategori KB}

KB Non Hormonal $\quad$ KB Hormonal

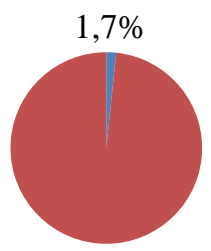

$98,3 \%$

\section{Jenis KB}

$\square$ Kalender $\square$ Pil $\square$ Suntik 1 Bulan $\square$ Suntik 3 Bulan

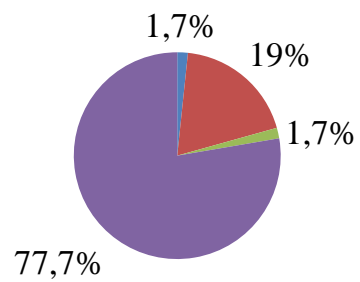




\section{Kegiatan /Pelaksanaan}

Hasil dari penyuluhan yang dilakukan dalam pengabdian masyarakat ini yaitu mayoritas pengetahuan ibu meningkat terkait manajemen perawatan ibu akseptor KB. Penyuluhan yang dilakukan yaitu memberikan informasi tentang keluarga berencana, metode $\mathrm{KB}$, aktivitas fisik, dan nutrisi bagi ibu.

Menurut Notoatmodjo menyatakan bahwa factor yang mempengaruhi perilaku kesehatan seseorang adalah tingkat pengetahuan. Pengetahuan ibu meningkat setelah diberikan penyuluhan perawatan ibu akseptor KB. Pengetahuan yang tinggi mendorong peserta untuk bersikap dan memutuskan metode KB yang cocok bagi ibu, aktivitas fisik dan nutrisi yang diperlukan bagi ibu.

Responden pada pengabdian masyarakat ini adalah lansia di panti tresna werdha dan puskesmas Paal X Dimana Jumlah Lansia 140 peserta

\section{Tabel 1. Pelaksanaan Kegiatan}

\begin{tabular}{|c|c|}
\hline $\begin{array}{l}\text { Pondok } \\
\text { Pesantren }\end{array}$ & Jumlah Peserta \\
\hline $\begin{array}{c}\text { Posyandu } \\
1\end{array}$ & $\begin{array}{l}\text { 1. Mengukur Tekanan Darah } \\
\text { 2. Menimbang Berat Badan } \\
\text { 3. Menentukan IMT } \\
\text { 4. Mendokumentasikan hasil pemeriksaan } \\
\text { 5. Memberikan Penyuluhan, konseling dan } \\
\text { buku panduan }\end{array}$ \\
\hline $\begin{array}{c}\text { Posyandu } \\
2\end{array}$ & $\begin{array}{l}\text { 6. Mengukur Tekanan Darah } \\
\text { 7. Menimbang Berat Badan } \\
\text { 8. Menentukan IMT } \\
\text { 9. Mendokumentasikan hasil pemeriksaan } \\
\text { 10. Memberikan Penyuluhan, konseling dan } \\
\text { buku panduan }\end{array}$ \\
\hline $\begin{array}{c}\text { Posyandu } \\
3\end{array}$ & $\begin{array}{l}\text { 11. Mengukur Tekanan Darah } \\
\text { 12. Menimbang Berat Badan } \\
\text { 13. Menentukan IMT } \\
\text { 14. Mendokumentasikan hasil pemeriksaan } \\
\text { 15. Memberikan Penyuluhan, konseling dan } \\
\text { buku panduan }\end{array}$ \\
\hline $\begin{array}{c}\text { Posyandu } \\
4\end{array}$ & $\begin{array}{l}\text { 16. Mengukur Tekanan Darah } \\
\text { 17. Menimbang Berat Badan } \\
\text { 18. Menentukan IMT } \\
\text { 19. Mendokumentasikan hasil pemeriksaan } \\
\text { 20. Memberikan Penyuluhan, konseling dan } \\
\text { buku panduan }\end{array}$ \\
\hline
\end{tabular}




\section{KESIMPULAN}

Berdasarkan kegiatan pengabdian yang dilakukan, sebanyak 121 yang mengikuti kegiatan pendidikan kesehatan perawatan ibu akseptor KB di Wilayah Kerja Puskesmas Simpang Sungai Duren Kabupaten Muaro
Jambi yang didampingi oleh petugas puskesmas dan kader.

Diharapkan pihak puskesmas dan kader tetap aktif untuk memberikan edukasi dan pembaharuan ilmu kepada ibu akseptor KB. Dinas kesehatan terkait untuk dapat memfasilitasi kegiatan.

\section{DAFTAR PUSTAKA}

1. Erna Sofyan Sjukrie. Perlindungan Hak-Hak Anak Yang Melakukan Pelanggaran Hukum. Konvensi Media Advokasi Dan Penegakan Hak-Hak Anak. Vol III (3). 2003.

2. WHO. Millennium Development Goals (MDGs). Jakarta: United Nation. 2008.

3. Badan Pusat Statistik. Proyeksi Penduduk Indonesia 2010-2035. Jakarta: Badan Pusat Statistik. 2013.

4. $\quad$ Badan Pusat Statistik Provinsi Jambi. Provinsi Jambi dalam Angka 2018. Jambi: CV. Salim Media. 2018.

5. Hikmat, Harry. Strategi Pemberdayaan Masyarakat. Bandung: Penerbit Humaniora. 2004.

6. Kementerian Kesehatan RI. Buletin Jendela Data \& Informasi Kesehatan: Situasi Keluarga Berencana di Indonesia. Jakarta: Kemenkes RI. 2013.

7. Saptari, Ratna \& Holzner, Brigitte.Perempuan Kerja dan Perubahan Sosial "Sebuah Pengantar Studi Perempuan". Jakarta: Kalyanamitra. 1997.

8. Ife, Jim. Community development: Creating community alternatives-vision, analysis and practice. Australia: Longman Pty Ltd.1995.

9. Swift C, Levin G. Empowerment: An Emerging Mental Health Technology. JPrimary Prevention, USA.1987.

10. Sumodiningrat, Gunawan. Pemberdayaan Masyarakat dan Jaring Pengaman Sosial. Jakarta: Gramedia Pustaka Utama. 1998.

11. Anitasari, Dini S, Mellly Setyawati, Sri Wahyuni. Kebijakan pemberdayaan Perempuan di Indonesia Pasca Orde Baru (Studi Kasus di Provinsi Jawa Barat, DI Yogyakarta dan Sumatera Barat). SCN CREST. 2010.

12. Hashemi, S. M., Schuler, S. R., \& Riley, A. P. Rural Credit Programs andWomen's Empowerment in Bangladesh. World Development , 24 (4), 635-653. 1996.

13. Suratun, dkk. Pelayanan Keluarga Berencana dan Pelayanan Kontrasepsi. Ed 1. Jakarta: Trans Info Media. 2008. Diakses http://ino.searo.who.int/EN/section3.html

14. Hartanto, H. Keluarga Berencana dan Kontrasepsi. Jakarta: CV Muliasari. 2011.

15. Forum Kesehatan Perempuan. Yayasan Lembaga Konsumen Indonesia. The Ford Foundation. Informasi Kesehatan Reproduksi Perempuan. Cetakan Pertama. Yogyakarta: Galang Printika. 2002.

16. Speroff, L. Pedoman Klinis Kontrasepsi. Ed 2. Jakarta: EGC. 2005.

17. Saroha, P. Kesehatan Reproduksi dan Kontrasepsi. Jakarta: Trans Media Info. 2009.

18. Apriyati, Sharly. Angka Kematian lbu dan Bayi di Provinsi Jambi Turun. Metro Jambi. Diakses dari https://metrojambi.com/read/2017/11/10/26650/angka-kematian-ibu-dan-bayi-di-provinsi-jambi-turun. 2017. 